\section{Three-level differential reward magnitude discrimination in rats}

CHARLES F. FLAHERTY ${ }^{2}$ and JOHN W. DAVENPORT, Regional Primate Research Center, University of Wisconsin, Madison, Wis. 53706

In two experiments conducted in a discrete-trial fixed-ratioleverpress situation, rats clearly discriminated among three stimuli associated with large reward ( 5 or 11 pellets), small reward (1 pellet), and nonreward. The course of acquisition and extinction was mapped for measures of start speed, ratio speed, and foodcup entrance behavior. Throughout acquisition and in the early portion of extinction there was an inverse relationship between leverpress speed and foodcup entrance responses. Resistance to extinction varied directly with amount of reward in within-S comparisons.

Previous studies of discrete-trial instrumental discrimination between differing amounts of reward have involved two discriminative stimuli and two associated reward magnitudes (e.g., Black, 1968). Two experiments are reported here in which three levels of reward magnitude were manipulated within Ss in a discrete-trial leverpress situation. In the first experiment distinctive stimuli were associated with 5-, $1-$, and 0 -pellet reward conditions in a go/no-go discrimination paradigm. In the second experiment the acquisition and extinction of an 11-1-0 discrimination was examined. In addition, goal responses (foodcup entrances) prior to completion of the instrumental response were recorded in both phases of Experiment 2.

EXPERIMENT 1

Subjects and Apparatus

The Ss were 12 naive male Hol tzman rats, approximately 130 days old at the start of the experiment. The Ss were reduced to $85 \%$ of their ad lib weight and maintained at that level by once-a-day feeding throughout the experiment. The apparatus, two Gerbrands Model C test chambers equipped with retractable levers, has been described in detail elsewhere (Flaherty \& Davenport, 1968).

Procedure

Pretraining consisted of magazine training (Day 1, 60 45-mg pellets delivered on a variable interval $30-\mathrm{sec}$ schedule), freeoperant barpress training (Day 2, 20 reinforced barpresses), and transitional discrete-trial barpress training (Day 3, 20 trials in which there was a progressive increase from one to five presses per trial required for a single-pellet reward).
On Days 4-24, all Ss were trained on a discrimination in which 5-, 1-, and 0-pellet trials (six of each) were intermixed in 18-trial sessions. Three different trial sequences, each with first order transitional effects equated, were used in random order across days. Trials were cued by distinctive stimuli (flashing cue light mounted above the lever position, click of a relay pulsed at $10 / \mathrm{sec}$, and a $10 / \mathrm{sec}$ pulsed, mediumfrequency tone) which were consistently associated with the reward levels. Two Ss were assigned randomly to each of the six possible cue-reward combinations. Trial onset was signaled by houselight onset, cue onset, and presentation of the lever. The lever was retracted and appropriate reward delivered immediately after completion of the fifth leverpress. Ten seconds after response completion the cue and houselight turned off and a variable intertrial in terval of 30 sec ensued.

\section{Results}

Mean start speeds (reciprocal of the latency of the first barpress) to the stimuli signaling the three levels of reward are presented in Fig. 1.It is clear from the figure that the Ss responded differentially to all three levels of reward. Analysis of variance, ignoring cues as a factor, indicated a significant Magnitude by Blocks interaction $(F=10.63, \mathrm{df}=12,132, \mathrm{p}<.01)$. Subsequent analysis utilizing Fisher's 1sd procedure $(\mathrm{p}=.05$, one-tailed) indicated that both 5- and 1-pellet speeds were significantly faster than 0-pellet speeds in Blocks 3-7, and 5-pellet speeds were faster than 1-pellet speeds in Blocks 4-7.

\section{EXPERIMENT 2}

Subjects and Apparatus

The Ss were six naive, male, 115-day-old Holtzman rats reduced to $80 \%$ of their ad lib weights. The Ss were run in a Lehigh Valley retractable-lever chamber equipped with a recessed foodcup and photobeam mounted across the entrance of the foodcup. The foodcup was located in the center of the response panel at floor level. The lever was positioned to the left of the foodcup, 3 in. above floor level.

\section{Procedure}

Pretraining was similar to Experiment 1 with the exception that on Day 220 discrete barpress training trials were given instead of 20 free-operant presses. Discrimination training again consisted of 18 trials per day with the intermixture of six 11-pellet, six 1-pellet, and six nonrewarded trials governed by the same stimulus sequences as were used in Experiment 1. Thirty acquisition sessions and 12 extinction sessions were given. The stimuli were the same with the exception that the flashing light stimulus was the houselight instead of the cue light mounted over the lever. One $\mathrm{S}$ was assigned to each of the six possible cue-reward groups. Postresponse trial duration was extended to $12 \mathrm{sec}$ and the intertrial interval was a VI $90 \mathrm{sec}$. In extinction, all three cues were presented as in acquisition, but only a 12-sec nonrewarded period followed completion of the five lever responses. A 1-min trial limit was imposed throughout the experiment.

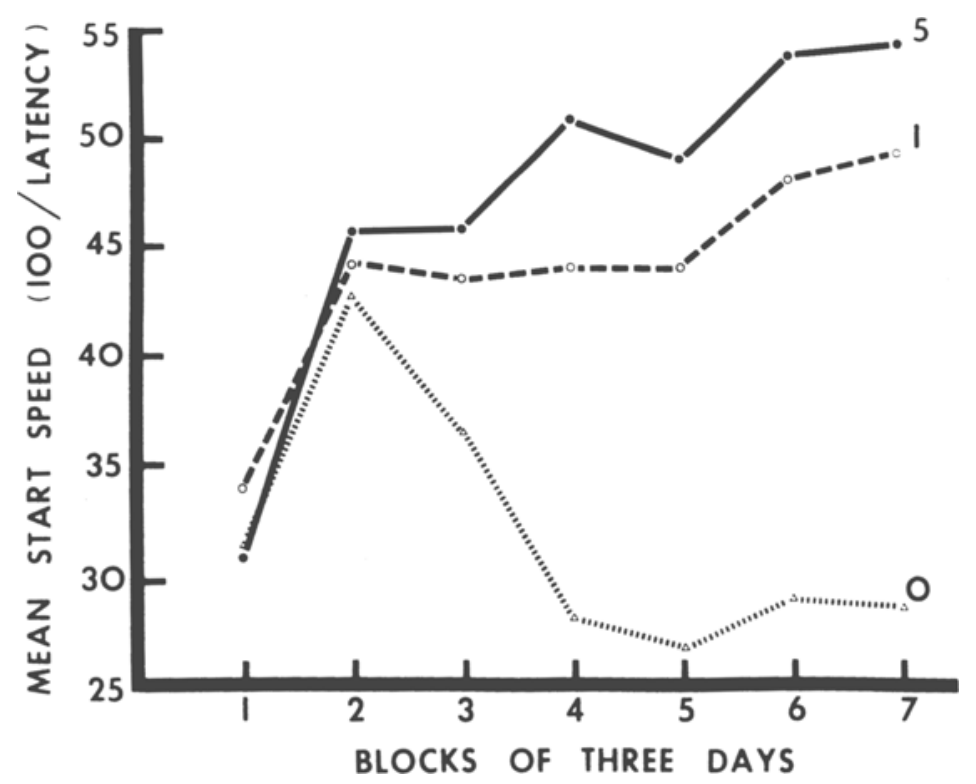

Fig. 1. Mean start speed to stimuli signaling five-, one-, and zero-pellet reward. 


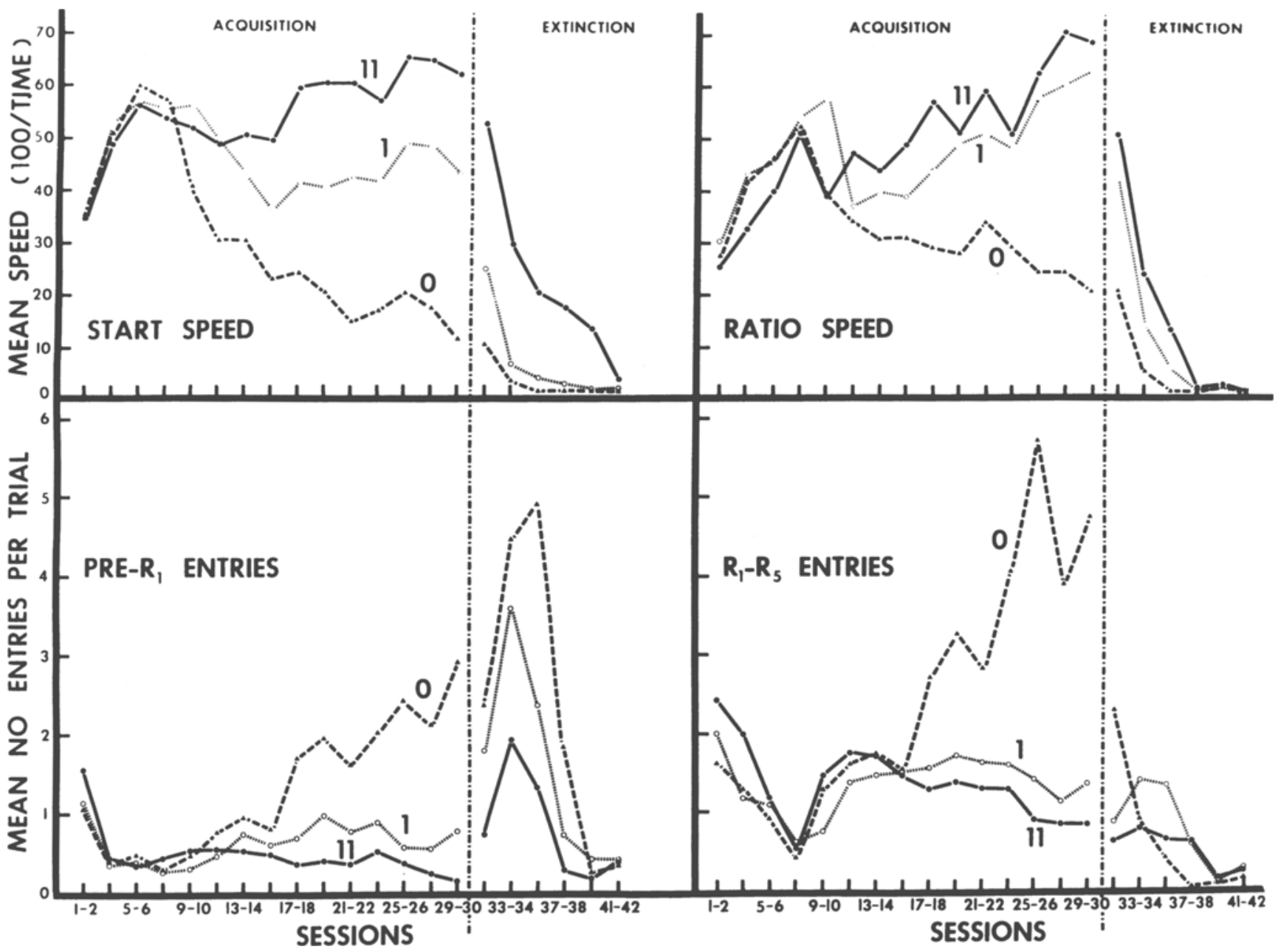

Fig. 2. Top panels: Mean start and ratio speeds, in acquisition and extinction, to stimuli signaling 11-, 1-, and 0-pellet reward. Bottom panels: Frequency of foodcup entrances prior to first leverpress (left panel) and between the first and fif th leverpresses (right panel).

Four response measures were recorded: (a) reciprocal of the time from trial onset to the first leverpress (start speed),(b) reciprocal of the time from the first to the fifth leverpress (ratio speed), (c) frequency of foodcup entrances between trial onset and first leverpress (pre-R1), and (d) frequency of foodcup entrances between the first and fifth lever responses (R1-R5).

\section{Results and Discussion}

As in the case of the 5-1-0 rats, start speed measures revealed clear evidence of discrimination among all three cues (upper left panel of Fig. 2). The Magnitude by Blocks interaction was highly significant $(F=6.47$, $\mathrm{df}=28,140, \mathrm{p}<.001$ ). Subsequent lsd tests $(\mathrm{p}=.05$, two-tailed) showed that 11- and 1-pellet start speeds were significantly higher than 0-pellet speeds in Sessions 11-30 and 9-30, respectively, and 11-pellet speeds were higher than 1-pellet speeds in Sessions 15-30.

With the ratio speed measure (upper right panel of Fig. 2), a significant Magnitude by Blocks interaction was also found $(F=3.56$, $\mathrm{df}=28,140, \mathrm{p}<.001$ ). Subsequent lsd tests showed that 11-pellet ratio speeds were significantly higher than 0-pellet speeds in Sessions 15-30, 1-pellet speeds were higher than 0-pellet speeds in Sessions 9, 10, and 17-30, and 1-pellet speeds were higher than 11-pellet speeds in Sessions 9 and 10.

The speed data in extinction supported the differential reward magnitude results of Davenport \& Flaherty (1969) in showing greater resistance to extinction to the large-reward stimulus and extended this finding to the case involving nonreward cues as well. When the start speeds in 2-day blocks were subjected to a shape function analysis (Anderson, 1963); a significant effect of acquisition magnitude emerged $(\mathrm{F}=10.22, \mathrm{df}=2,10, \mathrm{p}<.01)$, reflecting the fact that relative rate of extinction under 11-pellet cues was slower than under 1-or a-pellet cues. Thus, although a similar analysis of converted ratio speeds failed to show significant differences in extinction rate, it is becoming more firmly established that resistance to extinction is directly proportional to acquisition reward magnitude in within-S manipulations (e.g., Spear
\& Spitzner, 1969; Davenport ${ }^{3}$ ), whereas an inverse relationship has been a standard finding in between-groups reward magnitude studies (e.g., Hulse, 1958; Wagner, 1961).

The two lower panels of Fig. 2 show foodcup entrance measures that are virtual mirror images of the corresponding speed measures throughout the acquisition period. This relationship persisted until the midpoint of extinction, after which foodcup entrance behavior extinguished along with the extinction of the lever response. Analyses of the foodcup measures in acquisition and extinction revealed a pattern of significant effects that was highly similar to that of the speed measures: Magnitude by Blocks interactions were significant for the pre-R1 $(F=4.54, d f=28,140, p<.001)$ and R1-R5 $(F=3.96, \quad$ df $=28,140$, $p<.001)$ measures in acquisition and the pre-R1 measure in extinction $(F=2.39$, df $=10,50, p<.05)$.

The most surprising feature of these data was the high frequency of foodcup entrances in the presence of the 0 -pellet cue 
near the end of acquisition and on nearly all trials in the early portion of extinction. This finding suggests that, as a result of pretraining and the initial acquisition trials, two response tendencies-approach to the lever and approach to the foodcup-became highly dominant over all other response tendencies. Thus, when lever-approach (highest in the response hierarchy early in acquisition) was weakened by nonreinforcement (on 0-pellet trials in acquisition and all trials in extinction) or small reward (on 1-pellet trials), the Ss reverted to the response tendency which in early acquisition was second-ranked in the hierarchy (foodcup-approach) and did not select lower-ranked members of the hierarchy until both the first- and second-ranked responses were sufficiently weakened in extinction. It remains an interesting question as to whether more extended acquisition training would reveal an eventual decrement in foodcup approaches on 0-pellet trials prior to extinction or whether within-S factors, such as stimulus generalization, operating in differential conditioning situations, would maintain such behavior at a fairly high level.

\section{REFERENCES}

ANDERSON, N. H. Comparison of different populations: Resistance to extinction and transfer. Psychological Review, 1963, 70, 162-179.

BLACK, R. W. Shifts in magnitude of reward and contrast effects in instrumental and selective learning: A reinterpretation. Psychological Review, 1968, 75, 114-126.

DAVENPORT, J. W., \& FLAHERTY, C. F. Extinction of differential reward magnitude discrimination in a discrete bar-pressing situation. Psychonomic Science, 1969, 14, 29-30.

FLAHERTY, C. F., \& DAVENPORT, J. W Noncontingent pretraining in instrumental discrimination between amounts of reinforcement. Journal of Comparative \& Phy siological Psychology, 1968, 66, 707-711.

HULSE, S. H. Amount and percentage of reinforcement and duration of goal confinement in conditioning and extinction. Journal of Experimental Psychology, 1958, 56, 48-57.

SPEAR, N. E., \& SPITZNER, J. H. Influence of degree of training and prior reinforcer magnitude on contrast effects and resistance to ex tinction within-S. Journal of Comparative \& Physiological Psy chology, in press.

WAGNER, A. R. Effects of amount and percentage of reinforcement and number of acquisition trials on conditioning and extinction. Journal of Experimental Psychology, $1961,62,234-242$.

\section{NOTES}

1. Supported by Grant FR00167 from the National Institutes of Health. We thank James Bassett, Diane Ejch, and Louis Gonzalez for their assistance.

2. Now at Rutgers, The State University, New Brunswick, N.J.

3. Unpublished manuscript.

\section{Avoidable punishment and self-punitive behavior'}

ROBERT S. BEECROFT, University of North Dakota, Grand Forks, N.D. 58201, and BONNIE G. FISHER, University of Iowa, Iowa City, Iowa 52240

In an effort to increase the proportion of Ss displaying self-punitive running, punishment in the last 2 ft of the runway was made avoidable during extinction if the rat reached the goal box in less than $2 \mathrm{sec}$. Other Ss were punished on every trial or not punished during extinction following avoidance training. Punished animals exhibited persistent running. Eleven of the 20 punishment-avoidance Ss completed the maximum 100 extinction trials. For these nonextinguishing Ss learning of punishment avoidance was similar to ordinary avoidance learning, whereas extinguishers were markedly inferior in avoidance performance.

In the self-punitive behavior experiment which preceded this one, 10 of the 60 punished rats completed the maximum 100 extinction trials (Beecroft, Fisher, \& Bouska, 1967, Experiment 3). Since nonpunished controls with comparable training extinguish in 10-15 trials, on the average, the rat completing the 100th trial has put on a pretty good show. The animal has kept the $E$ engaged for $2 \mathrm{~h}$ and has run an eighth of a mile in short sprints. In the present experiment we sought to increase the proportion of Ss running all the way.

Although self-punitive behavior is basically the phenomenon of increased resistance to extinction of punished behavior (cf. Brown, in press, for a thorough discussion of the literature), it has been observed that running speed increases during punished extinction (Melvin \& Smith, 1967; Beecroft \& Bouska, 1967a; Beecroft, 1967; Beecroft \& Brown, 1967). If there is a positive relationship between running speed and resistance to extinction, as seems likely, then any manipulation which increases running speed for the average $S$ should also increase the persistence of the running response. With a fixed-distance punishment zone (e.g., last $2 \mathrm{ft}$ of the alley), running faster shortens punishment duration and, putatively, the reduction in punishment duration differentially reinforces fast running. If the rat by running very fast could avoid punishment, at least on some trials, then greater resistance to extinction might accompany the increased running speed.
This experiment compared avoidable punishment with punishment on every trial and no punishment. Punishment was made avoidable by delaying the electrification of the punishment zone for $2 \mathrm{sec}$ from the start of the trial. Under this scheme, fast runs go unpunished and runs only slightly slower than the cutoff shrink the punishment zone. METHOD

The runway consisted of a duplex start box, a 6-ft alley, and a large black goal box (cf. Brown, Martin, \& Morrow, 1964, for details). The Ss were handled for 2 days and both trained and tested on the third day. The rat was trained to one avoidance with a 3-sec interval. On the next trial extinction testing began and continued until $S$ failed to enter the goal box within $60 \mathrm{sec}$ or completed 100 trials. For Condition NP there was no punishment during extinction. In the $\mathbf{P}$ condition the last $2 \mathrm{ft}$ of the alley were electrified on all extinction trials. In the AP (avoidable punishment) condition onset of the shock in the punishment zone was delayed $2 \mathrm{sec}$ from the start of the trial. The 2-sec value was a nominal one; electronically timed records showed the punishment avoidance interval was 1915 msec. An animal in the AP condition entering the goal box within $1915 \mathrm{msec}$ avoided shock. Training and punishment shock intensity was $55 . \mathrm{V}$ ac through $10 \mathrm{~K}$ resistance. Goal box detention was $30 \mathrm{sec}$, the intertrial interval was approximately $60 \mathrm{sec}$, and there was no warning signal. The Ss were 60 female hooded rats $87-102$ days old. Twenty were randomly assigned to each condition. Two additional animals were discarded. One extinguished on the first trial before encountering the punishment contingency and the other animal was found to be ill before training.

\section{RESULTS}

Figure 1 shows the familiar self-punitive phenomenon, viz, punished Ss exhibited greater resistance to extinction than nonpunished Ss. The mean number of extinction trials completed was 15.8 for the $\mathrm{NP}$ group compared with 67.0 and 67.2 for the $P$ and AP groups. The medians were 9.5 for NP, 69 for $P$, and 100 for AP. The ogival curves for $\mathrm{P}$ and $\mathrm{AP}$ conditions cross twice. For 50 or so trials more $\mathbf{P}$ Ss continued running. Beyond Trial 54 no AP animal extinguished, while roughly one $P$ rat dropped out in each block of 10 trials. At the end of 100 trials, six of the Ss punished on every trial were still running, while 11 of the AP animals were still on their feet. 